\title{
Acessibilidade em setor de aulas da Universidade Federal do Rio Grande do Norte: a percepção da pessoa com deficiência
}

\author{
Accessibility in classrooms sector of Federal University of Rio \\ Grande do Norte: the perception of people with disabilities
}

ISABELA DANTAS DE SANTA CRUZ

Mestranda em Arquitetura e Urbanismo, UFRN, isabelasantacruz2@hotmail.com

MARIANA NOBRE DA COSTA MARINHO

Mestranda em Arquitetura e Urbanismo, UFRN, mariananobrearquiteta@gmail.com

\begin{abstract}
RESUMO
Este artigo tem como objetivo contribuir com a discussão a respeito da acessibilidade nos espaços universitários e revelar a importância do ponto de vista dos usuários na avaliação dos ambientes. Ele é parte de uma pesquisa mais ampla, realizada no segundo semestre do ano de 2019 , relacionada à Avaliação Pós-Ocupação do Setor de Aulas IV da Universidade Federal do Rio Grande do Norte, porém, neste estudo, aborda-se apenas os aspectos da pesquisa voltados para o usuário. Assim, este artigo foca a compreensão da experiência e percepção de pessoas com deficiência e/ou mobilidade reduzida em relação ao uso do ambiente construído com segurança e autonomia. Tal objetivo foi alcançado por meio da técnica do passeio acompanhado. Os resultados mostram que as mudanças impróprias no uso dos ambientes acessíveis, o não atendimento integral à legislação, a falta de manutenção e a gestão inadequada dos recursos existentes são os principais obstáculos enfrentados por estes usuários na utilização do espaço estudado.
\end{abstract}

PALAVRAS-CHAVE: Avaliação Pós-Ocupação, acessibilidade, passeio acompanhado.

\section{ABSTRACT}

The objective of this article is to contribute with the discussion regarding accessibility to university spaces and assert how important users perception is analyzing places. It is part of a broader research, developed on the last semester of 2019, linked to the Post-Occupation Evaluation of the Classrooms Sector IV at the Federal University of Rio Grande do Norte, however, it addresses only aspects of the research related to the user. It focuses especially on understanding the experience and perception of people with disabilities and/or reduced mobility in regard to the use of the built environment with safety and autonomy. This objective was achieved through the technique of accompanied walking. The results show that the improper changes in the use of accessible environments, the noncompliance with the legislation, the lack of maintenance and the inadequate management of existing resources are the main obstacles faced in the use of the studied area.

KEYWORDS: Post-Occupation Evaluation, accessibility, accompanied walk. 


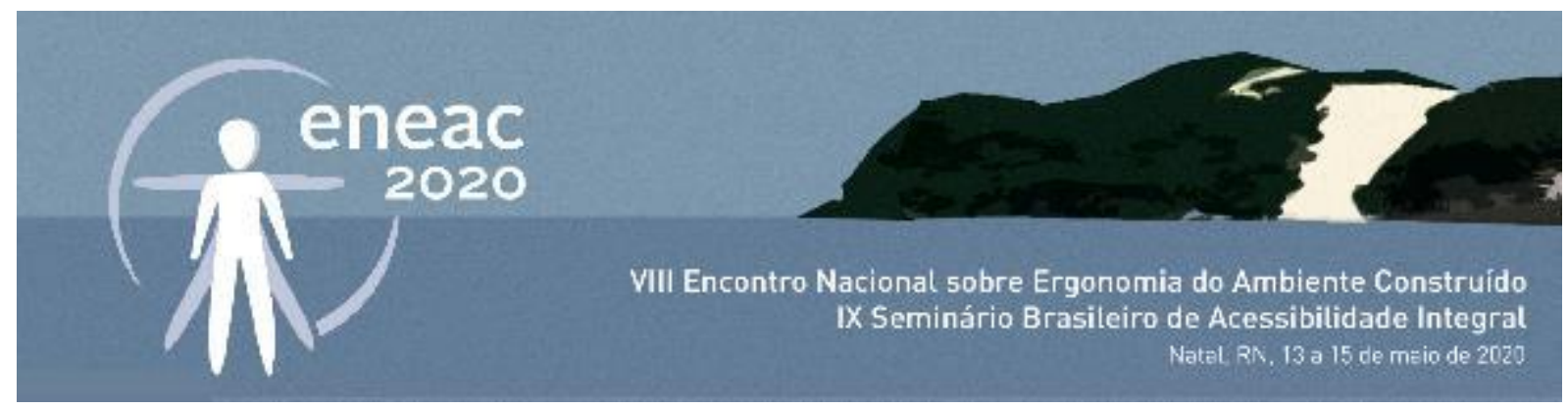

\section{INTRODUÇÃO}

Em 2011, o Relatório Mundial sobre a Deficiência estimou que existiam mais de 1 bilhão de pessoas com deficiência no mundo (OMS, 2012). No Brasil, a mais recente pesquisa do Instituto Brasileiro de Geografia e Estatística apontou que $23,9 \%$ da população brasileira apresentava algum tipo de deficiência (IBGE, 2012; REDE JUNTOS, s/d); além disso, quando observada a relação entre brasileiros com deficiência e as regiões geográficas do pais, o Nordeste estava em primeiro lugar, apresentando o percentual de $26,63 \%$ de habitantes nessas condições.

Segundo a Lei no 13.146/2015, que instituiu a Lei Brasileira de Inclusão da Pessoa com Deficiência (2015), considera-se, a teor do disposto no Art. 2 o do referido Diploma Legal, pessoa com deficiência:

(...) aquela que tem impedimento de longo prazo de natureza física, mental, intelectual ou sensorial, o qual, em interação com uma ou mais barreiras, pode obstruir sua participação plena e efetiva na sociedade em igualdade de condições com demais pessoas. (BRASIL, 2015)

Na Universidade Federal do Rio Grande do Norte, recorte analisado neste artigo, segundo dados fornecidos pela Comissão Permanente de Apoio a Estudantes com Necessidades Educacionais Especiais (CAENE/UFRN), existem atualmente 186 estudantes com algum tipo de deficiência que possuem vínculo ativo com a instituição (CAENE, 2020), sendo 165 pertencentes ao Campus Central (Natal) e, dentre estes, 15 estão ligados ao Centro de Tecnologia, onde a maior parte de suas aulas são ministradas no Setor IV, ambiente objeto do estudo aqui apresentado.

Sendo dever do Estado combater a exclusão social existente no país, sabe-se que, desde a redemocratização, foram criadas algumas políticas públicas, leis e decretos para fomentar a inclusão de pessoas com deficiência na sociedade, a saber: a Política Nacional para a Integração da Pessoas com Deficiência (BRASIL, 1989); o Conselho Nacional da Pessoa com Deficiência - CONADE (BRASIL, 1999); a Política Nacional de Assistência Social - PNAS (BRASIL, 2004); o Plano Nacional dos Direitos da Pessoa com Deficiência (BRASIL, 2011); a Lei Brasileira de Inclusão (BRASIL, 2015) entre outros.

Não obstante, na prática, o que se percebe é a existência de muitas políticas, mas pouca execução, efetividade e eficiência, notadamente quando se leva em consideração a aplicação das normas técnicas no setor, como a NBR 9050 (ABNT, 2015), que, por sua vez, versa especificamente sobre as exigências que recaem sobre o ambiente construído.

Nesse sentido, mesmo considerando o arcabouço legal e algumas conquistas relacionadas à acessibilidade dos espaços, as pessoas com deficiência ainda enfrentam muitos desafios. Associado a isso, se o ingresso em uma universidade pública já se apresenta como um desafio inicial para muitas pessoas, quando se trata de pessoas com deficiência, aquele pode ser apenas o primeiro dentre tantos outros que poderão enfrentar ao frequentar a instituição de ensino. Isso porque esse grupo de alunos com algum tipo de deficiência também precisa vencer, diariamente, barreiras físicas para assistir aulas, utilizar laboratórios, banheiros, espaços de convivência e muitos outros tantos espaços existentes nas universidades.

Pensando nisso e com o objetivo de avaliar se a estrutura física da UFRN permite o acesso e uso autônomo e seguro por usuários com características e necessidades diversas, uma Avaliação Pós 


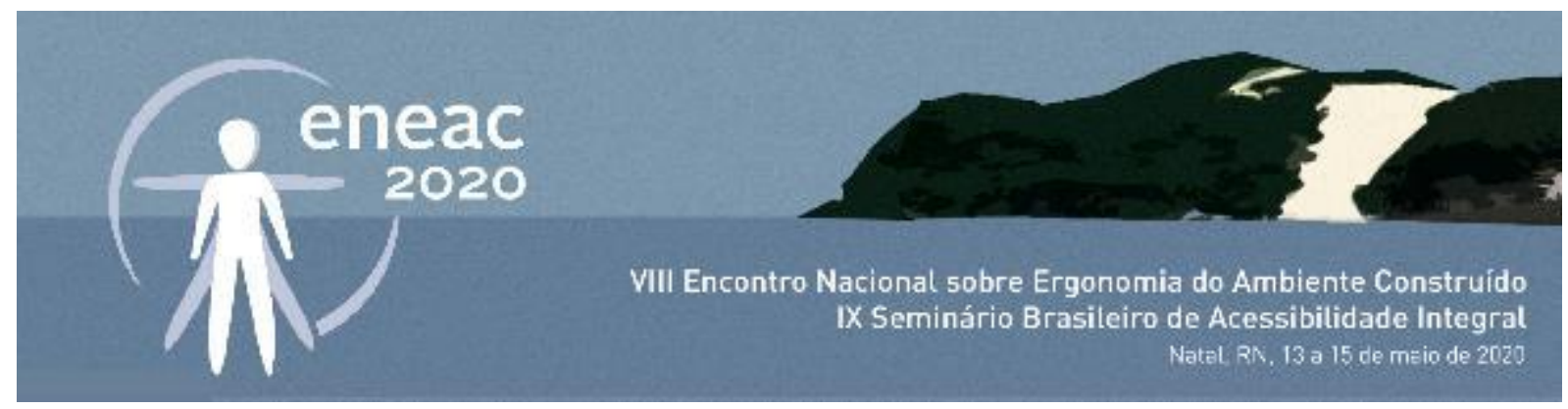

Ocupação foi realizada no Setor de Aulas IV da referida universidade no segundo semestre letivo de 2019 (SANTOS et al., 2019). Este setor é majoritariamente utilizado pelos alunos dos cursos das mais diversas Engenharias, Arquitetura e Urbanismo, servidores públicos e funcionários terceirizados.

A Avaliação Pós-Ocupação (APO) pode ser definida como uma “estratégia de investigação" (ELALI, 2010 , p.11) que utiliza um "conjunto de métodos e técnicas para avaliação de desempenho em uso de edificações e ambientes construídos que leva em consideração não somente o ponto de vista dos especialistas, mas também a satisfação dos usuários" (VILLA, SARAMAGO, GARCIA, 2016, p.9).

Dito isso, este artigo tem como objetivo específico compreender a experiência e percepção dos usuários em relação ao uso do ambiente construído com segurança e autonomia. Para tal fim, foi utilizada a técnica do passeio acompanhado com três alunos da instituição, todos vinculados à CAENE/UFRN.

\section{MÉTODO}

A pesquisa recorreu ao passeio acompanhado, técnica desenvolvida por Dischinger (2000) e que consiste em avaliar as condições de uso do espaço físico por meio da percepção do usuário em situações reais, iniciando por meio da definição de uma rota e ser percorrida e estudada. 0 pesquisador apenas acompanha o participante, não podendo ajuda-lo ou conduzi-lo ao longo do trajeto. Aquele toma notas das impressões e comentários dos usuários, além de ilustrar situações relevantes e significativas por meio de fotografias.

Por meio dessa técnica foi possível compreender o comportamento dos usuários diante de barreiras de acessibilidade existentes e de que maneira o ambiente os afeta. A Figura 1 ilustra parcela da UFRN onde os passeios acompanhados ocorreram, englobando o Setor de Aulas IV (representado pela cor amarela) e outros pontos comumente acessados pelos usuários deste setor como os estacionamentos (cinza), a parada de ônibus (laranja), Laboratórios de Arquitetura (azul), Edifício Bacharelado da Ciência e Tecnologia (rosa) e o Restaurante Universitário (verde).

Na escolha dos participantes, foi levado em consideração, principalmente, o tipo de deficiência que cada um deles apresenta, uma vez que se pretendia abordar na pesquisa percepções variadas. Para isto, inicialmente a Comissão Permanente de Apoio a Estudantes com Necessidades Educacionais Especiais (CAENE) da UFRN foi contactada, com a intenção de se obter informações a respeito dos usuários com algum tipo de deficiência vinculados ao Centro de Tecnologia, e, consequentemente, potencial usuário do Setor de Aulas IV.

Tendo em vista a constante ênfase dada a Pessoas em Cadeiras de Rodas (PCR) em diversos estudos relacionados a acessibilidade, optou-se por fazer o passeio acompanhado com pessoas com outros tipos de deficiência. A intenção é mostrar e discutir as dificuldades enfrentadas por elas, mas que muitas vezes passam desapercebidas por muitos e até mesmo pelas normativas. A CAENE forneceu o contato de estudantes com tipos de deficiências variadas e frequentadores do Setor IV (CAENE, 2020 - mensagem de e-mail às pesquisadoras). Dentre as pessoas indicadas, apenas duas se disponibilizaram a participar; diante disso, foram contatadas pessoas que possuíam menor proximidade com o setor. Finalmente, três pessoas aceitaram participar da investigação, todas vinculadas à universidade, embora apenas duas com aulas no Setor de Aulas IV. 


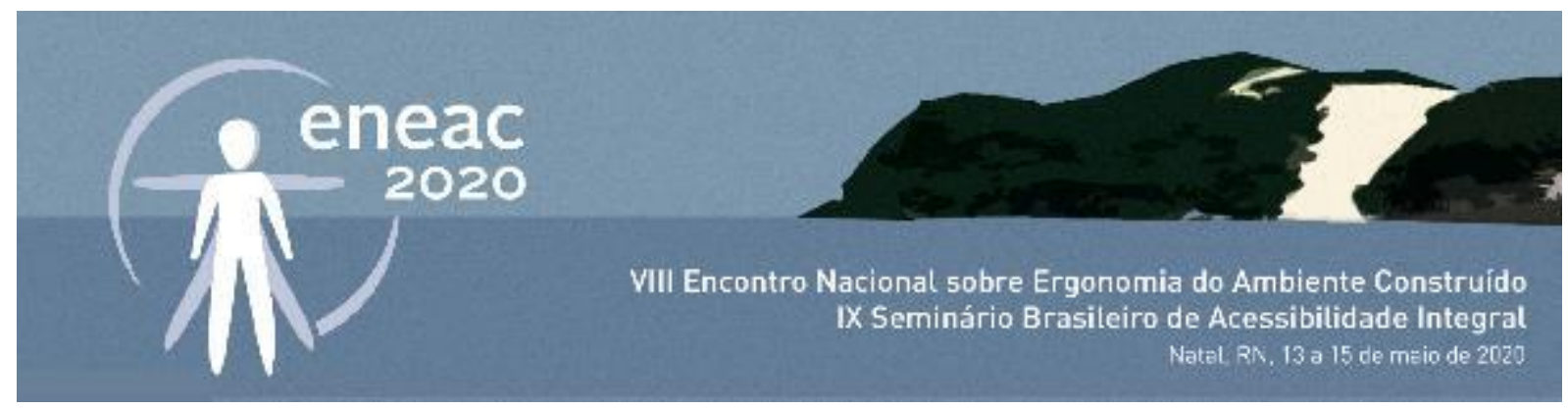

A fim de respeitar a identidade dos participantes, garantindo seu anonimato, eles serão denominados de A, B e C: o usuário A tem Síndrome de Mórquio ou Mucopolissacaridose IVA, apresentando baixa estatura; o usuário $B$ tem Displasia Condometafisária, apresentando baixa estatura e mobilidade reduzida; e o usuário $C$ é deficiente visual e apresenta cegueira total.

Uma vez estabelecidos os participantes desta atividade, iniciou-se a etapa de definição da rota a ser percorrida. A intenção era de que os pontos testados ao longo do percurso estivessem relacionados à rotina dos usuários, o que foi feito com as pessoas $A$ e $B$. Com a pessoa $C$, não frequentadora do local, o trajeto definido levou em consideração pontos e trechos com maior fluxo e uso do ponto de vistas das pesquisadoras.

Figura 1: Parcela da UFRN onde ocorreram os passeios acompanhados

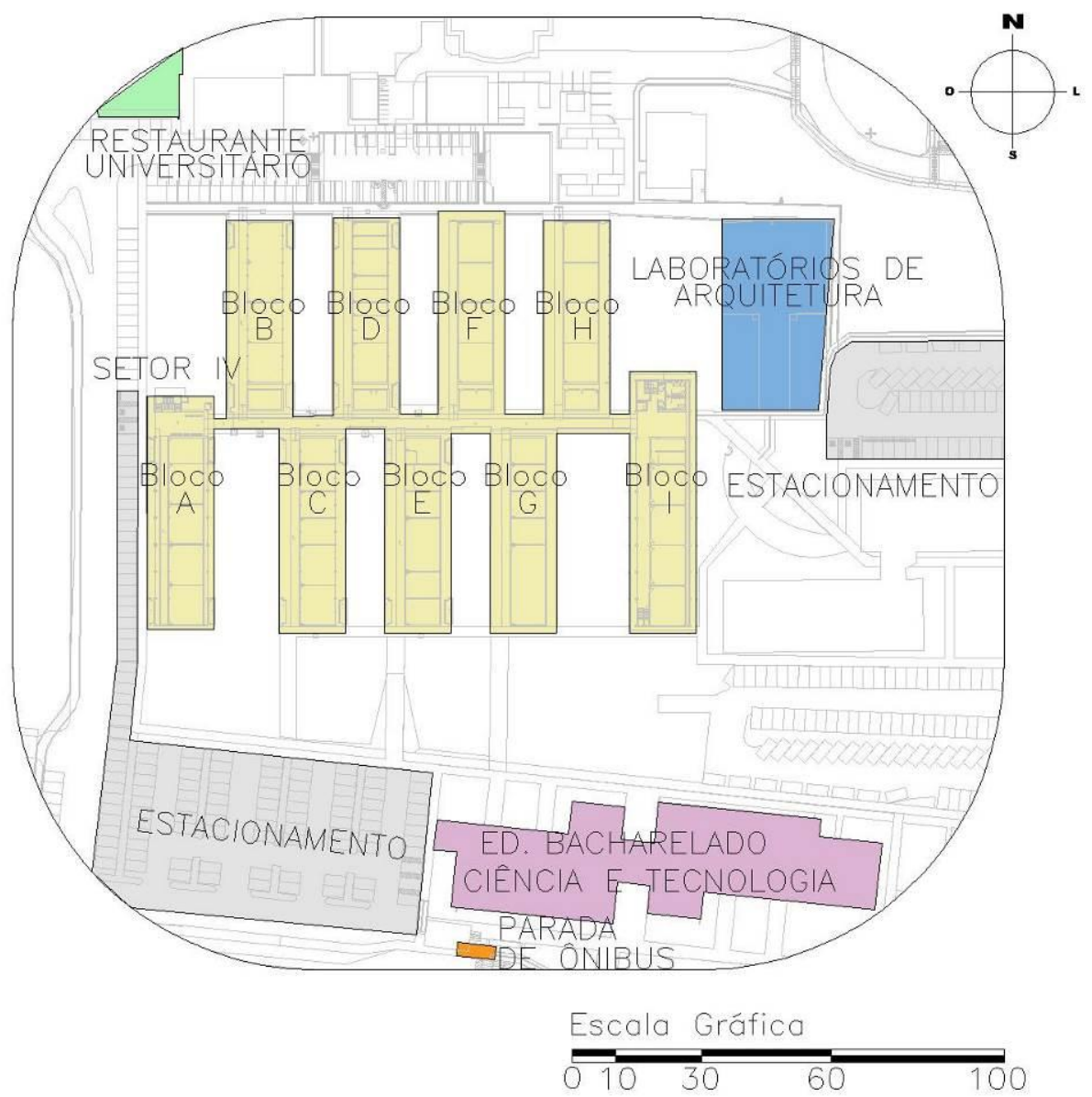

Fonte: Secretaria de Infraestrutura da UFRN editado pelas autoras, 2019. 


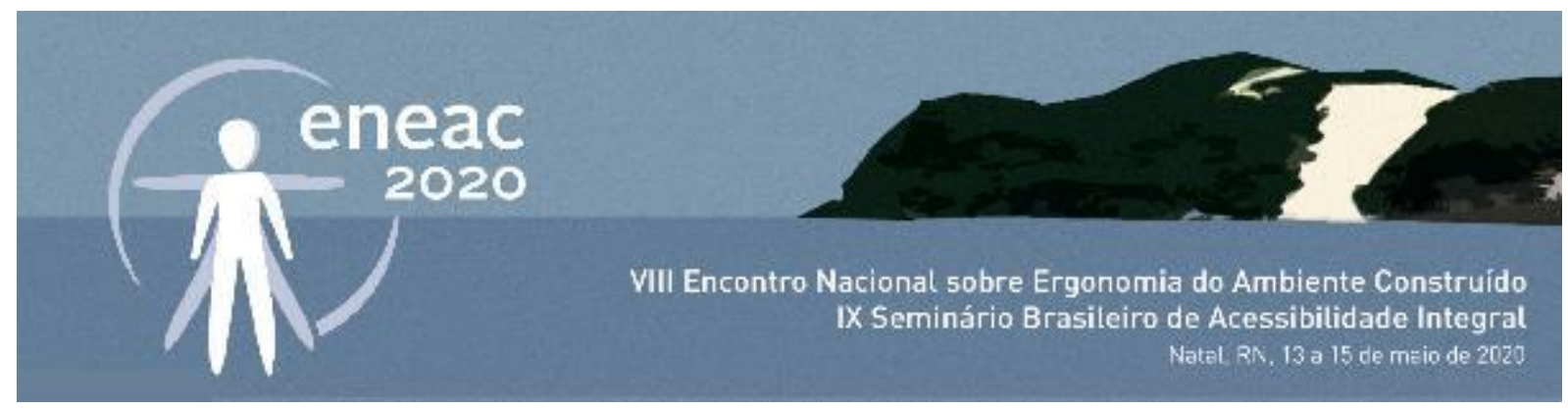

\section{RESULTADOS E DISCUSSÕES}

O primeiro aspecto conferido com os três participantes foi o acesso ao corredor central do Setor de Aulas IV a partir do estacionamento ou da parada de ônibus, a depender do meio de transporte usualmente utilizado pelo usuário para vir à universidade. Em segundo lugar foram verificados os bebedouros e demais mobiliários que estão dispostos ao longo das circulações horizontais entre os blocos de aula. Em seguida foram analisadas duas salas de aula, sendo a primeira delas a sala de estudos (situada no Bloco E, do Setor IV) e outra sala de aula habitualmente utilizada nas aulas teóricas dos participantes que frequentam o setor (com exceção do usuário C). Dois banheiros também foram incluídos no roteiro, sendo um coletivo pertencente à parte mais antiga do Setor (situado no bloco $\mathrm{H}$ ) e o outro de construção mais recente e acessível (bloco I). Por último, circulou-se pelos blocos A e I, dotados de diversos pavimentos, para verificação do acesso e da circulação vertical, sendo necessária a utilização de escadas e/ou plataforma de elevação vertical. Vale ressaltar que om o usuário $C$, o bloco I não foi acessado.

Na sequência, cada um desses percursos será ilustrado e descrito de modo a retratar a experiência vivenciada por cada um dos participantes no passeio acompanhado.

\section{Pessoa A}

A Figura 02 apresenta de forma detalhada o percurso feito pelo participante A e em seguida, será dado destaque aos pontos conflituosos percebidos no decorrer do passeio acompanhado.

O indivíduo utiliza carro particular como meio de transporte, o qual é conduzido pelo seu pai. Desta forma, o aluno não apresenta dificuldades em acessar o corredor central do Setor de aulas IV, tendo em vista que o condutor estaciona o veículo o mais próximo possível das salas em que a pessoa $A$ tem aulas (Figura 3).

Com relação à circulação vertical, foi relatado que a plataforma elevatória vertical está constantemente desligada e que é necessário pedir a um funcionário o seu ligamento. No entanto, no dia do passeio, de forma excepcional, a plataforma (Figura 4) estava em perfeitas condições de uso e o acesso ao segundo pavimento do bloco $A$ foi realizado sem nenhuma dificuldade. 

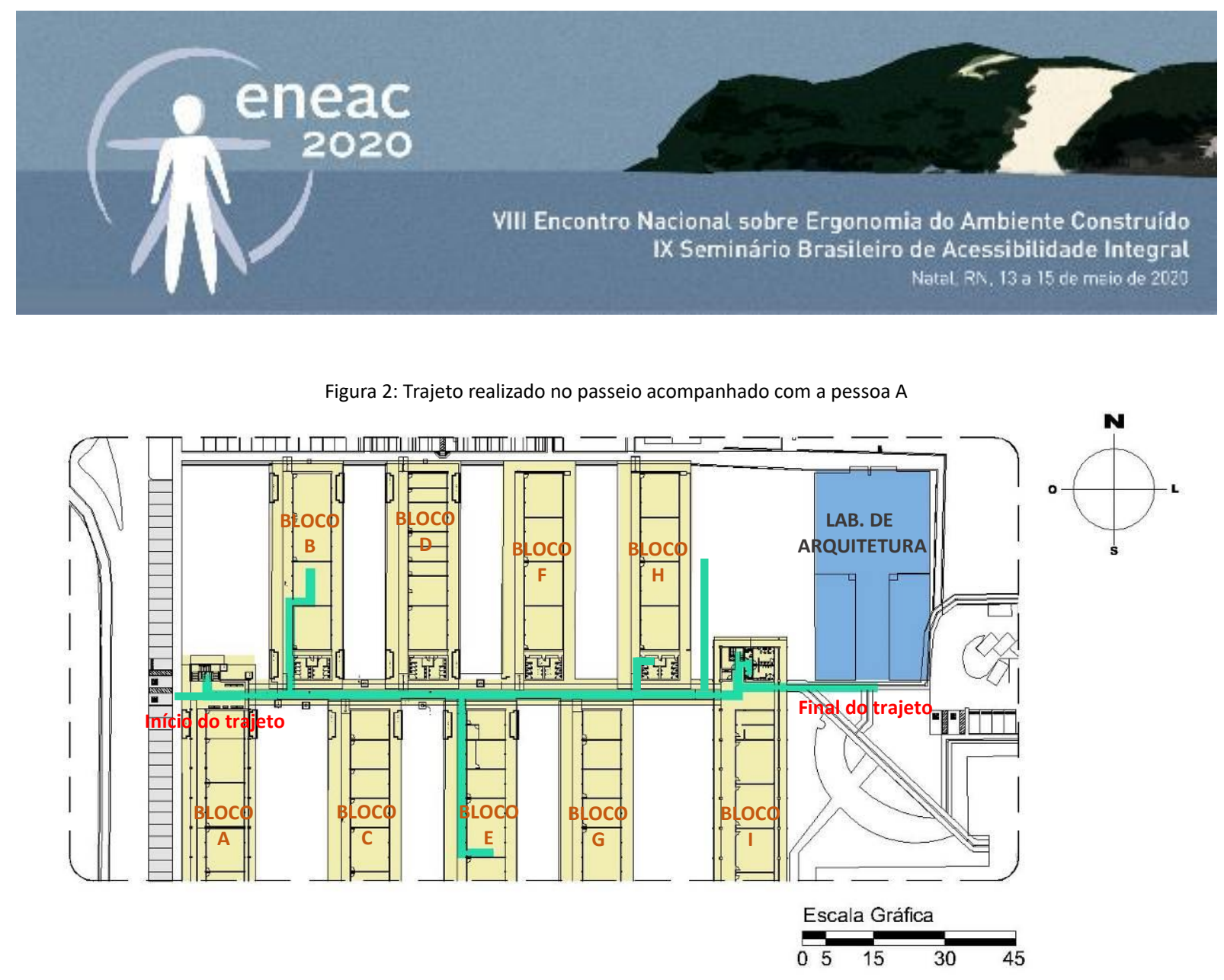

Fonte: Secretaria de Infraestrutura da UFRN editado pelas autoras, 2019.

Figura 3: Ponto de partida do passeio acompanhado com a pessoa A - Estacionamento à esquerda interligado ao corredor central do

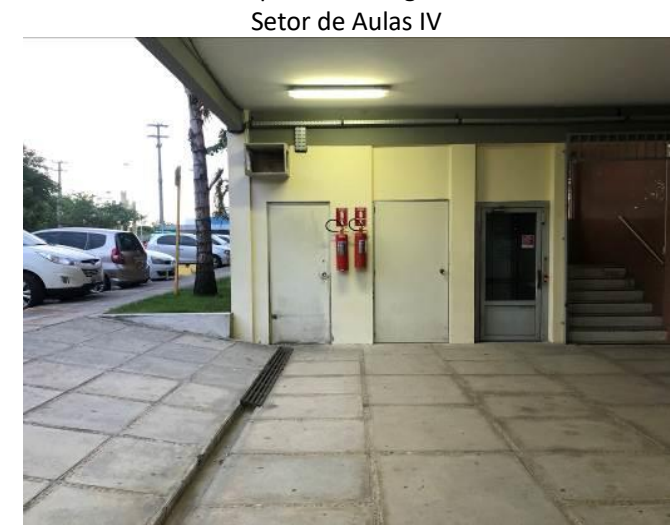

Fonte: Autoras, 2020.

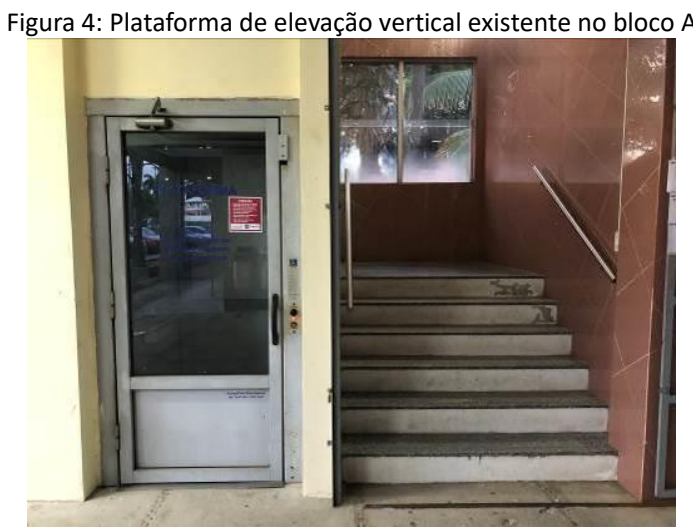

Fonte: Autoras, 2020.

Com relação aos banheiros, foi relatado que a unidade acessível com entrada independente (localizada no bloco I) se encontra constantemente fechada, mas, na ocasião desta atividade, ela estava aberta, sendo assim possível sua utilização. É importante ressaltar que foi percebido indícios de desvio de uso no ambiente, uma vez que ele estava sendo utilizado como depósito de material de limpeza, servindo para guardar vassouras, baldes, pá, rodo e panos, por exemplo, conforme pode ser visto na Figura 5.

Dando prosseguimento ao passeio e levando em consideração o relato do banheiro acessível, anteriormente citado, o participante foi questionado se conseguia utilizar os banheiros coletivos existentes nos blocos antigos do setor e ele alegou que sim. Após a resposta afirmativa, foi solicitado que o aluno utilizasse o banheiro do bloco $\mathrm{H}$ e verificou-se se ele consegue usar a bancada que 


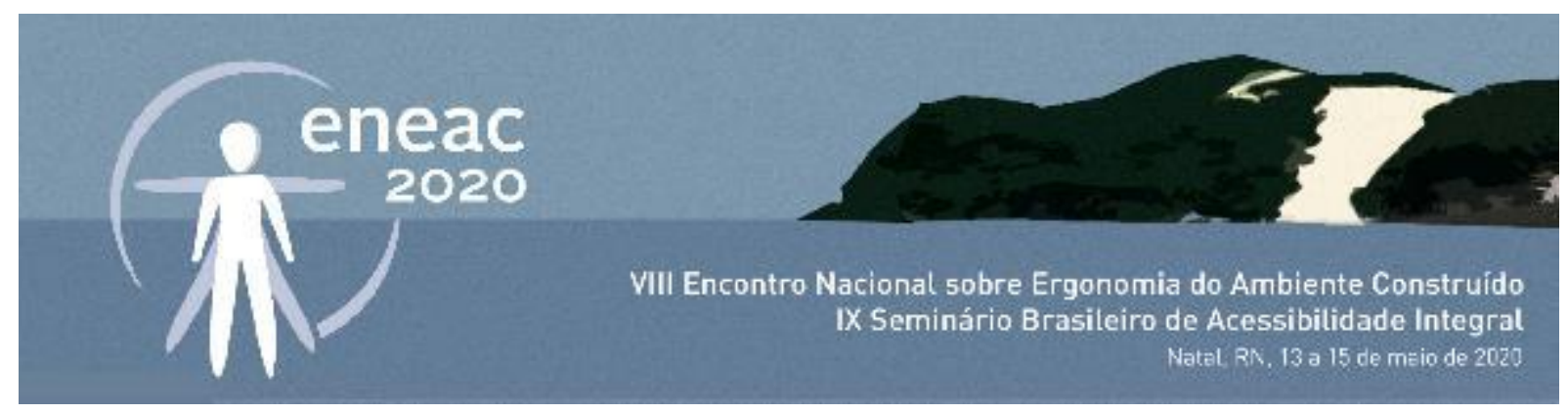

contém a cuba deste banheiro. Porém, ele declarou que só consegue utilizar este lavatório (Figura 6) porque ele é o mais baixo, se comparado com as demais bancadas existentes nos outros banheiros do mesmo setor. Ademais, a pessoa $\mathrm{A}$ afirmou não conseguir acessar o papel higiênico, pois, devido à falta de papeleira, ele é disposto no porta-objeto (Figura 7), que por sua vez, está fora da faixa de alcance estabelecida pela NBR 9050/2015. E, ainda, devido a altura do mobiliário, o usuário não consegue utilizar o mictório, enquanto a bacia sanitária é usada de forma satisfatória.

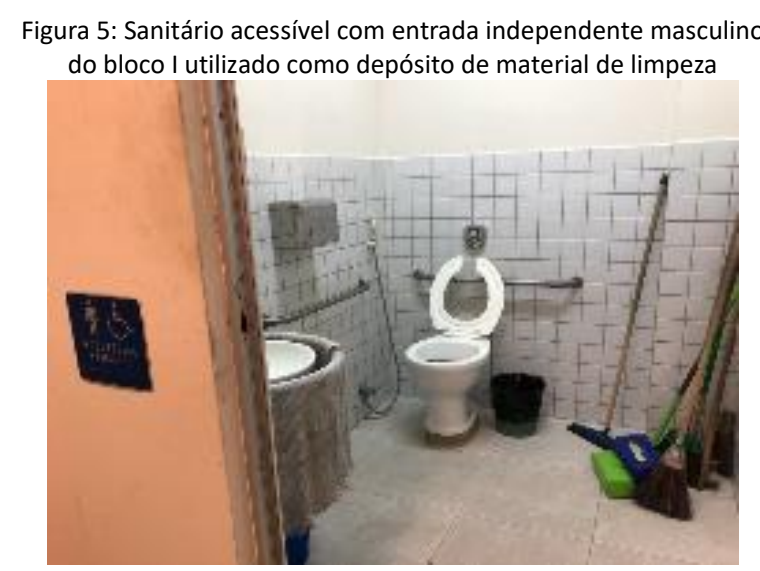

Fonte: Autoras, 2019.

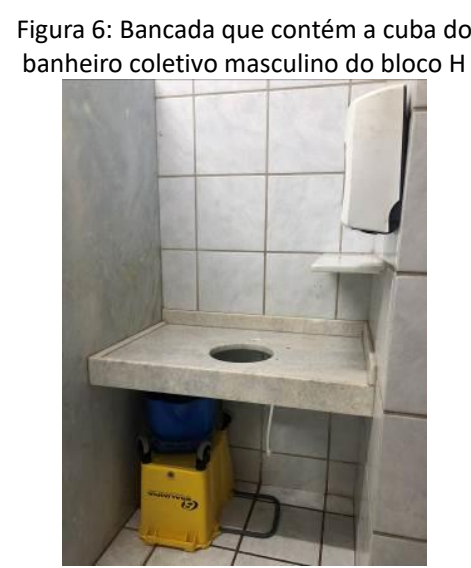

Fonte: Autoras, 2019.

Figura 7: Boxe comum do banheiro coletivo masculino com porta-objeto

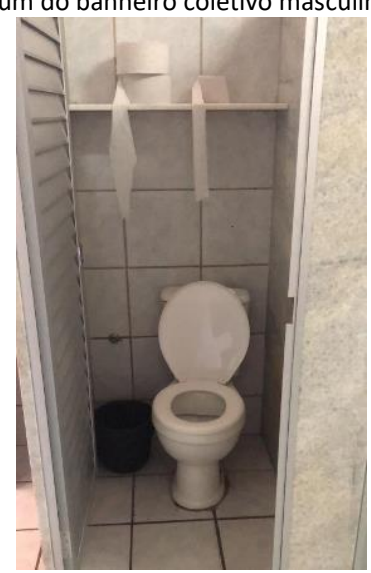

Fonte: Autoras, 2019.

Em se tratando dos mobiliários dispostos nos corredores do setor de aulas, foi percebido que, devido a altura das bicas do bebedouro, o usuário não consegue beber água neste tipo de equipamento (Figura 8), apenas nos bebedouros de garrafão. Ambos estão dispostos na circulação horizontal do Setor IV. No tocante ao mobiliário fixo (Figura 9) existente nas áreas de convivência (mesas e bancos de concreto), o usuário consegue usá-lo, mas não consegue sentar da forma convencional. Ele precisa ficar de joelhos no banco para alcançar a mesa. Foi constatado, então, que o banco não é ergonômico para ele. 


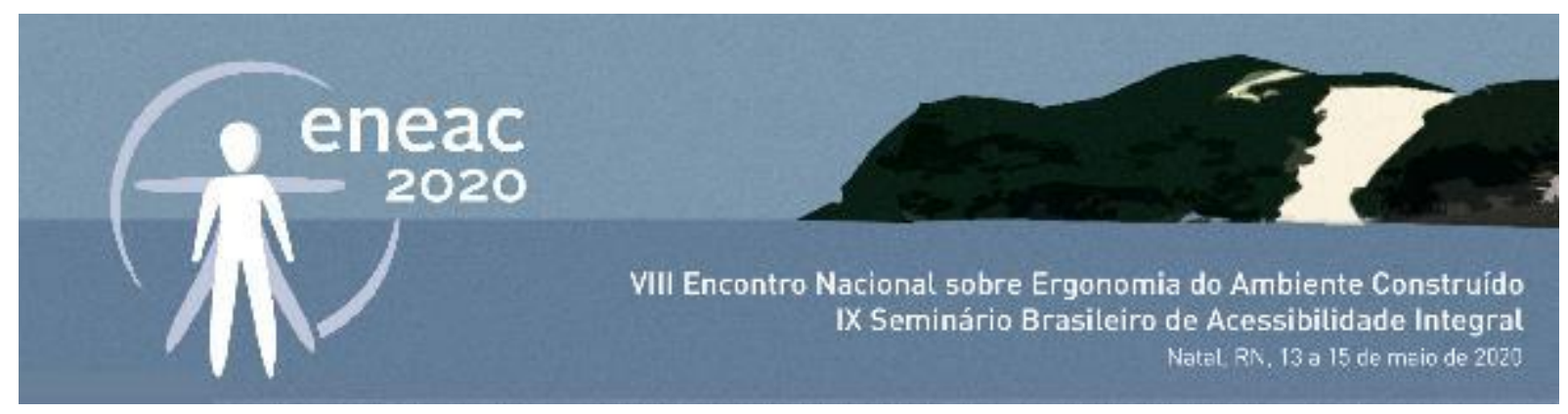

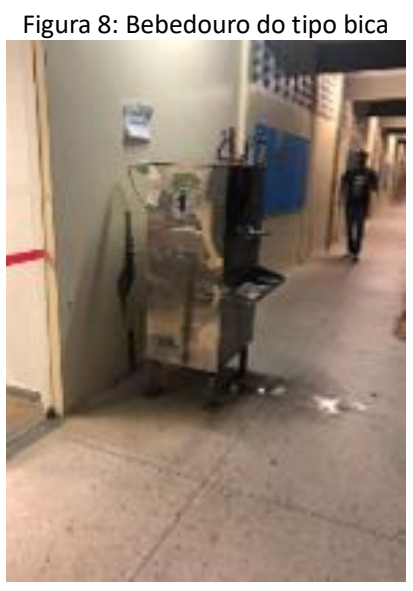

Fonte: Autoras, 2019.

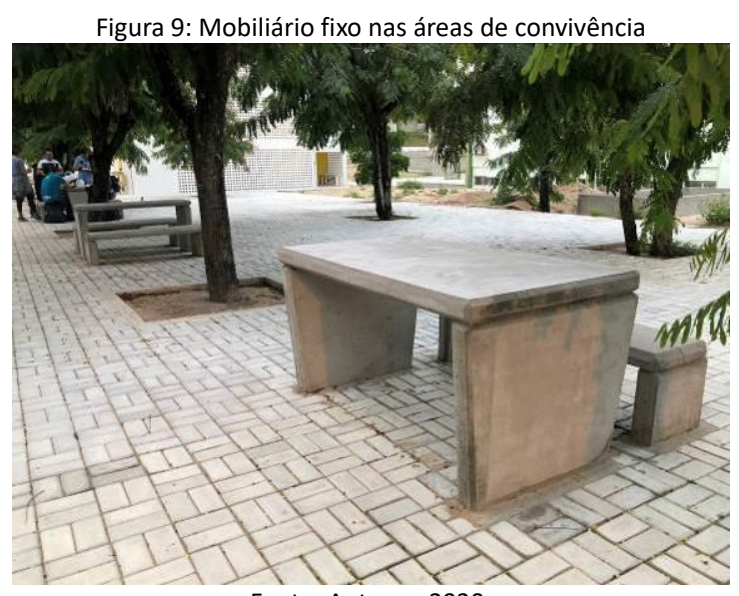

Fonte: Autoras, 2020

Retomando o quesito da circulação vertical, o único meio existente que interliga o térreo aos demais pavimentos do bloco I é a escada (Figura 10), não estando ela associada a nenhum equipamento eletromecânico de transporte vertical ou rampa. O indivíduo subiu um lance de escada de forma independente, mas relatou que o corrimão é muito alto para ele.

Na sala de estudos (Figura 11) localizada no bloco E (E4) e nas salas de aulas teóricas do bloco $A$ comumente utilizadas pelo estudante, ele afirmou que consegue utilizar as mesas e cadeiras de maneira satisfatória, mas foi observado que isso só é possível porque ele demonstrou que desenvolveu habilidades específicas para lidar com a sua deficiência e a falta de adequação dos locais que frequentemente utiliza.
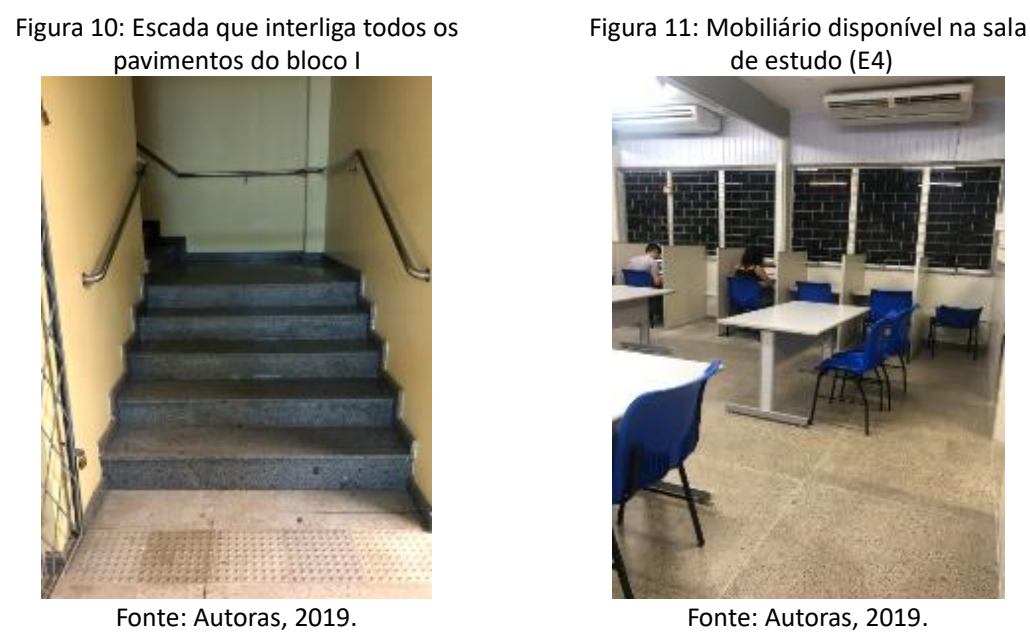

\section{Pessoa B}

O percurso realizado pela pessoa B está representado na Figura 12. Devido ao fato da participante frequentemente utilizar ônibus como meio de transporte, o ponto de partida escolhido para o passeio acompanhado foi a parada de ônibus do Setor IV (Figura 13). A usuária apresenta problemas em suas articulações e relatou ter dificuldade em fazer o trajeto até a circulação principal que 


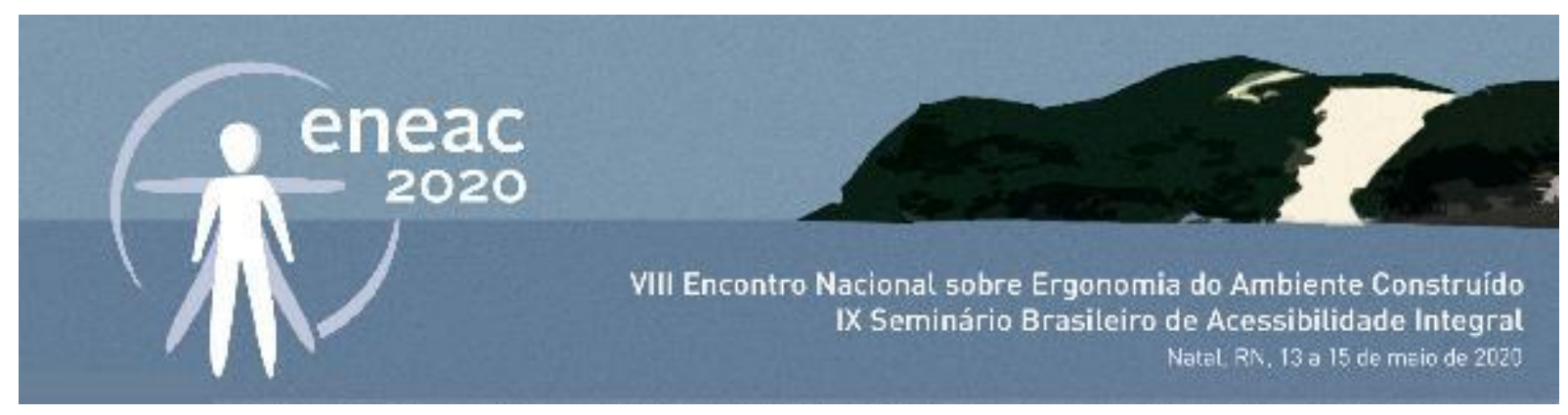

interliga os blocos de aulas do setor, pois necessita percorrer longas distâncias, já que no trajeto mais curto existe uma escada sem corrimãos (Figura 14), o que compromete e inviabiliza a sua utilização.

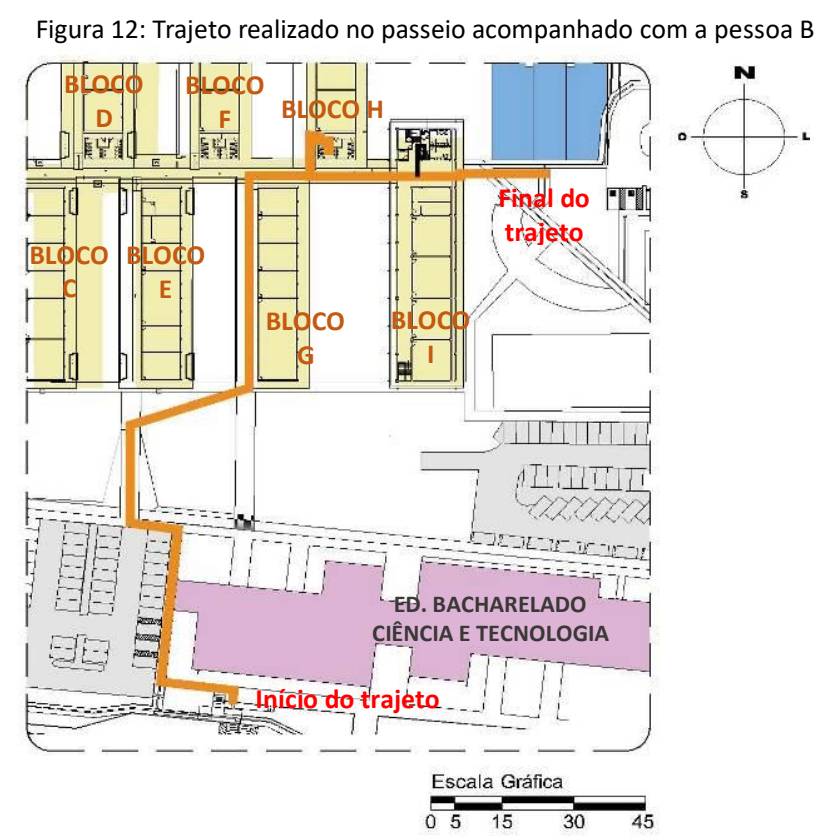

Fonte: Secretaria de Infraestrutura da UFRN editado pelas autoras, 2019.

Figura 13: Ponto de partida do passeio acompanhado com a

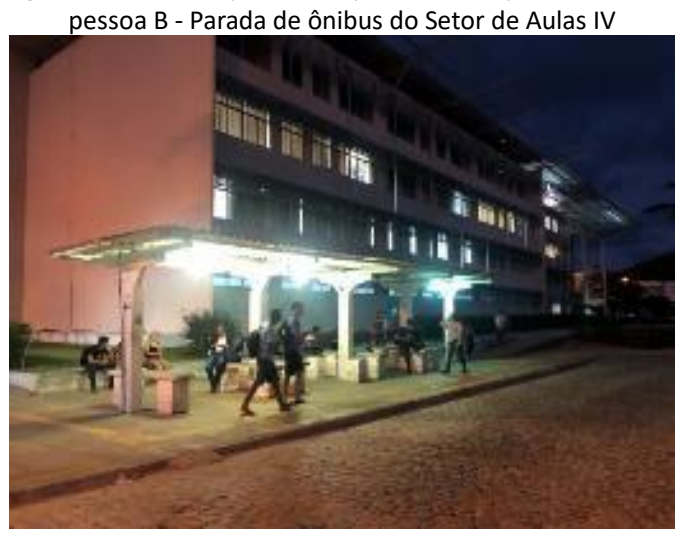

Fonte: Autoras, 2019.
Figura 14: Escada sem sinalização e equipamentos de segurança exigidos pela NBR9050/2015 e NBR 16537/2016

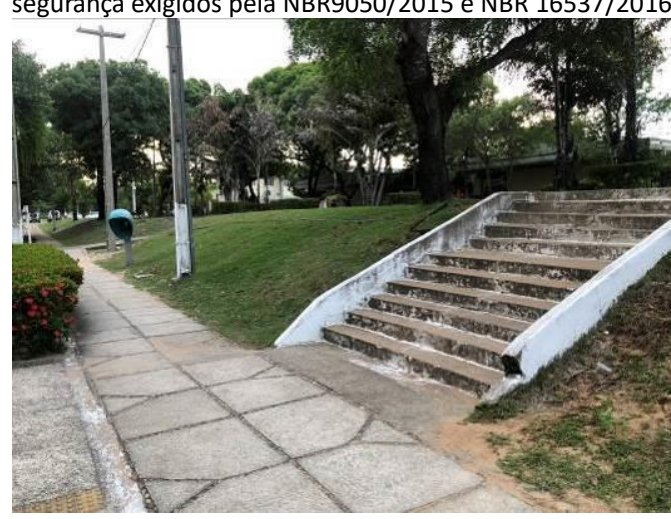

Fonte: Autoras, 2020

O trajeto escolhido pela usuária também sofre com a falta de manutenção e desgaste da superfície do piso, o que aumenta o risco de queda. Além disso, existem rampas com piso trepidante e instável, sem equipamentos de proteção como corrimãos, guarda corpo, sinalização, dentre outros itens, como pode ser percebido na Figura 15. Por fim, a estudante afirmou que após subir a rampa, caminha pela grama (Figura 16), fazendo um "atalho", pois o percurso anterior foi suficiente para deixá-la cansada. 


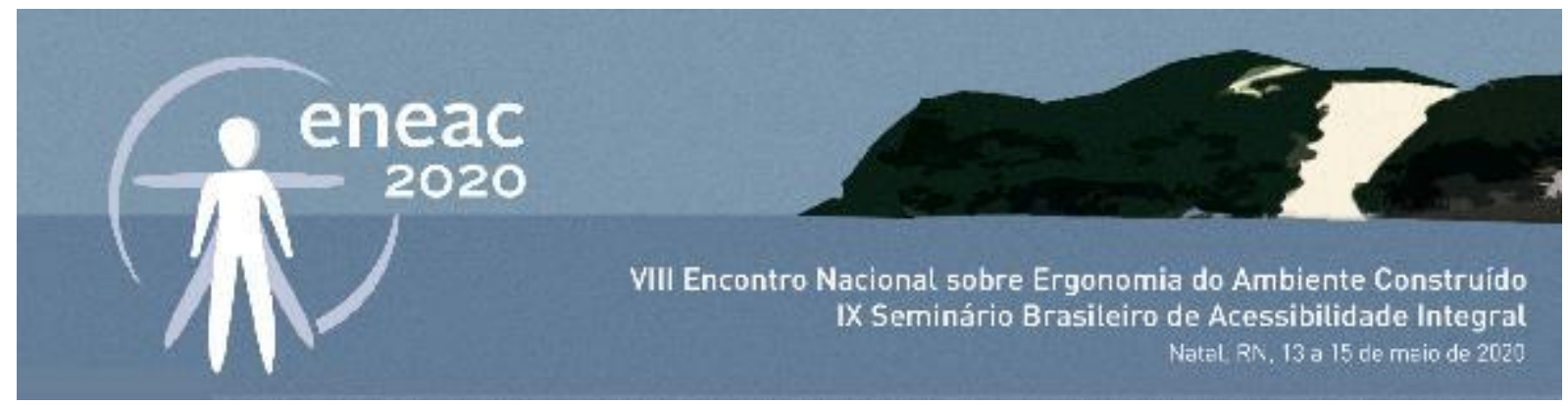

Ao chegar à circulação principal, optou-se por não incluir a sala de estudos (E4) no percurso com a participante $B$, pois ela não costuma utilizar este ambiente.

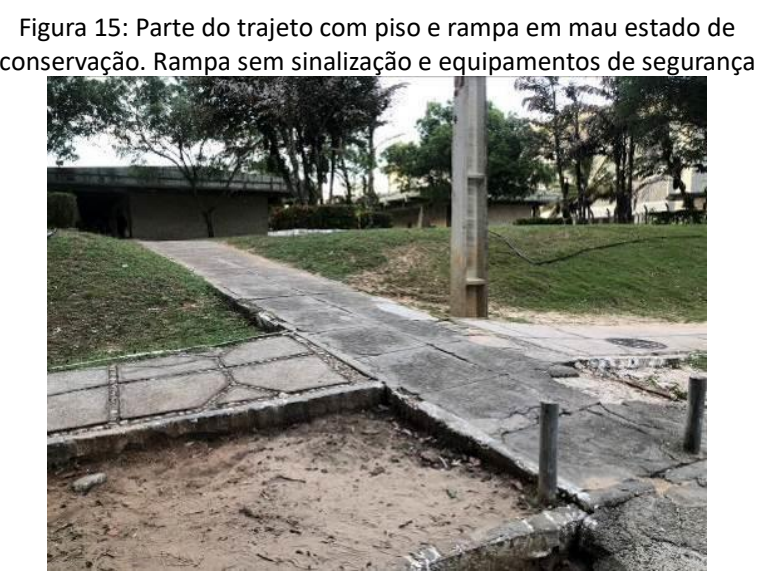

Fonte: Autoras, 2020.
Figura 16: Gramado utilizado pela pessoa B como atalho no caminho a ser percorrido até a circulação principal do setor IV

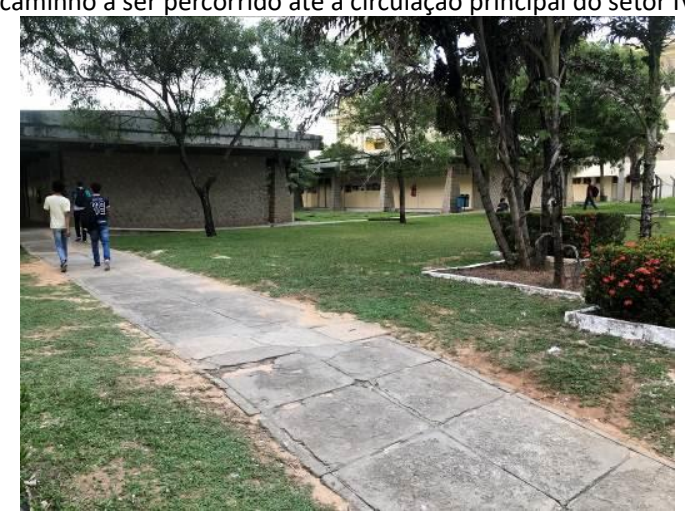

Fonte: Autoras, 2020.

Em relação aos banheiros, tanto o coletivo (que possui boxe acessível no seu interior) do bloco $\mathrm{H}$ quanto o acessível com entrada independente do bloco I, foram classificados como não satisfatórios pela participante. Para ela, a bacia sanitária do banheiro acessível com entrada independente (Figura 17) e a do boxe acessível do banheiro coletivo (Figura 18) são altas, enquanto que a existente na cabine de uso comum (mais estreita) é difícil de ser utilizada porque não possui barras de apoio laterais, como pode ser percebido na Figura 19. Segundo seu relato, o ideal para a sua condição seria um banheiro coletivo dotado de, pelo menos, um boxe com barras de apoio laterais. A usuária ainda expõe que o banheiro acessível com entrada independente do bloco I não está entre as suas frequentes escolhas, pois além de ser longe das salas de aula normalmente utilizadas por ela, está constantemente fechado. Diante das opções ofertadas pela universidade, a que melhor se adequa às condições da aluna é a bacia sanitária do boxe de uso comum do banheiro coletivo, mesmo que ela sinta dores nos braços ao ter que se apoiar nas divisórias de granito existentes para não entrar em contato com a superfície do vaso sanitário.

Figura 17: Sanitário acessível com entrada independente feminino do bloco I

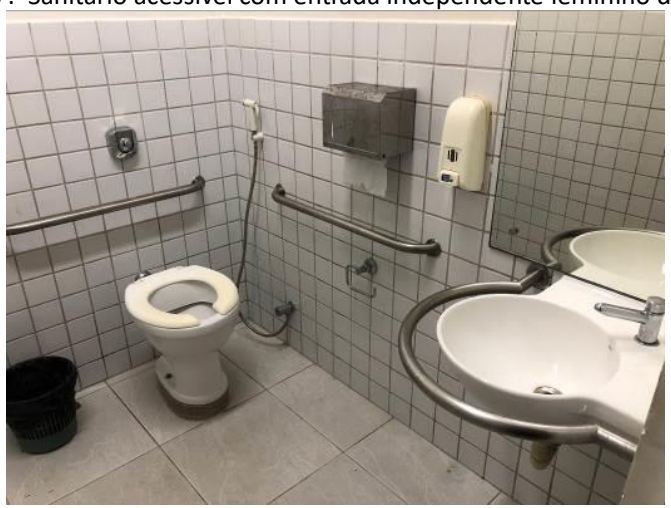

Fonte: Autoras, 2019. 


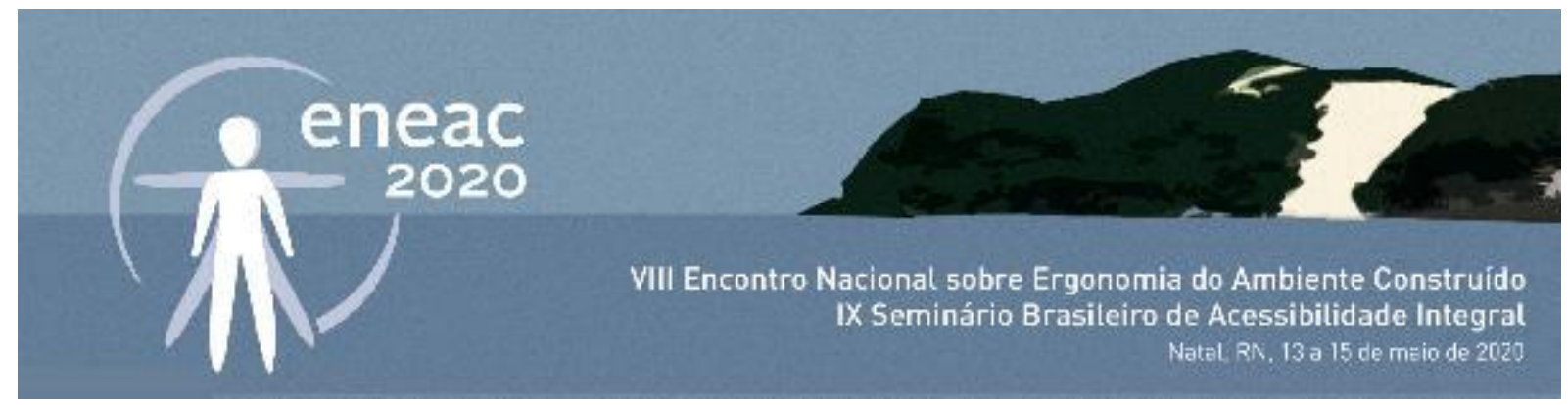

Figura 18: Boxe acessível do banheiro coletivo feminino do bloco $\mathrm{H}$

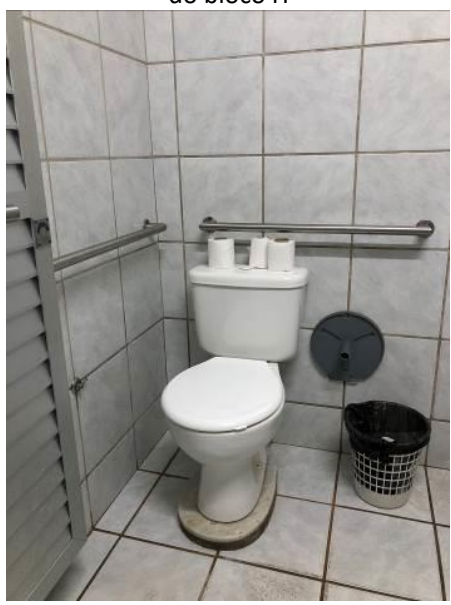

Fonte: Autoras, 2019.
Figura 19: Boxe comum do sanitário coletivo feminino do bloco $\mathrm{H}$

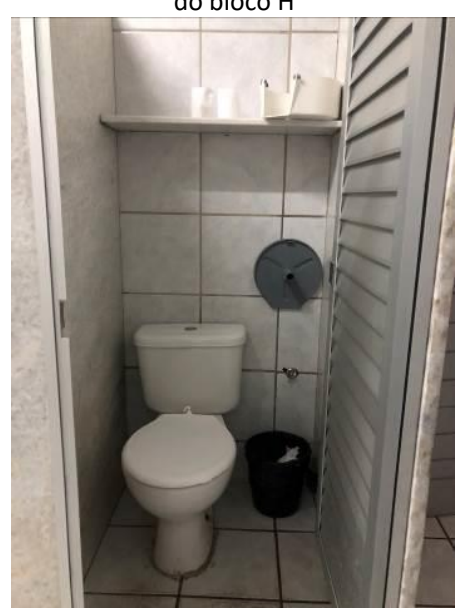

Fonte: Autoras, 2019.

No tocante às salas de aula usualmente utilizadas pela participante, esta relatou que as alturas das mesas e assentos são inadequadas. Seus pés não conseguem alcançar a superfície do piso, causando dores na coluna, e a altura da mesa causa dor nas articulações dos braços. A pessoa B ainda relatou que em determinada oportunidade chegou a solicitar a um docente a mudança de sala de aula de uma determinada disciplina que aconteceria no bloco I, porém não no pavimento térreo, devido às dores e desconfortos que sente ao subir lances de escada, causada pela sua mobilidade reduzida. No tocante às pranchetas - frequentemente utilizadas pelos alunos do curso de Arquitetura e Urbanismo - também foi relatado o seu desconforto ao utilizá-las por estas não estarem adequadas para sua condição física (Figura 20).

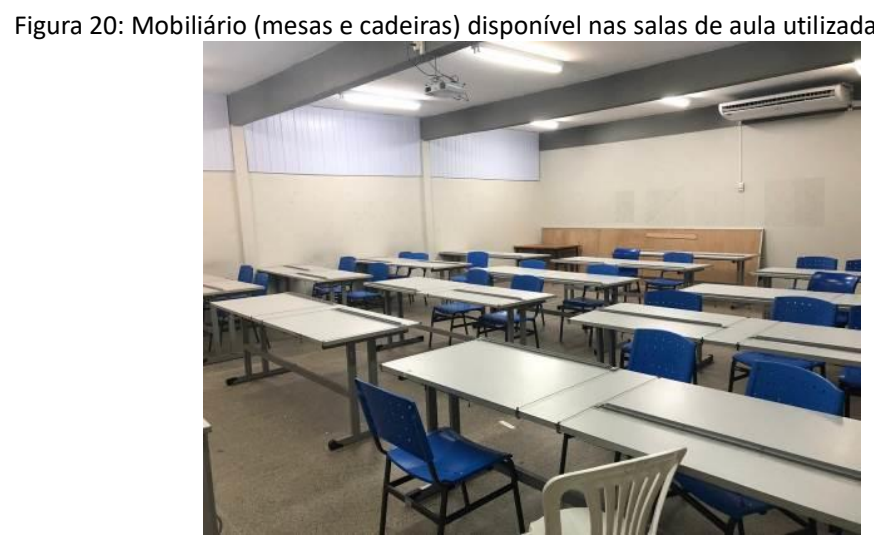

Fonte: Autoras, 2020.

Por último, quanto à circulação vertical (apenas por escada) que dá acesso a todos os pavimentos do bloco I, a aluna se diz insatisfeita com a altura dos espelhos dos degraus, assim como a das barras de apoio instaladas (Figura 9). Ela alegou que demanda muito esforço da sua parte para conseguir subir os lances da escada, por isso, seria ideal que as alturas desses elementos fossem inferiores às constatadas in loco.

\section{Pessoa C}




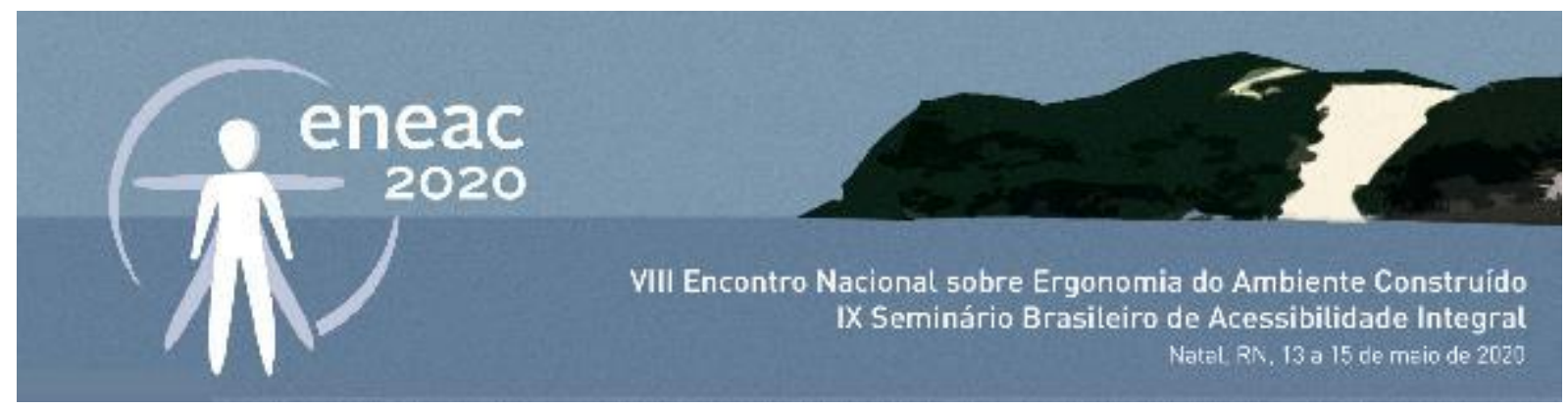

A Figura 21 ilustra o trajeto realizado pelo participante $C$ no passeio acompanhado. Diferente dos indivíduos $\mathrm{A}$ e $\mathrm{B}$, o indivíduo $\mathrm{C}$ apresentou maiores dificuldades com relação à utilização e circulação no Setor de Aulas IV. O fato de ele ser deficiente visual e não conhecer o local fez com que o passeio acompanhado precisasse ser feito de forma mais cautelosa, para que ele não sofresse nenhum acidente.

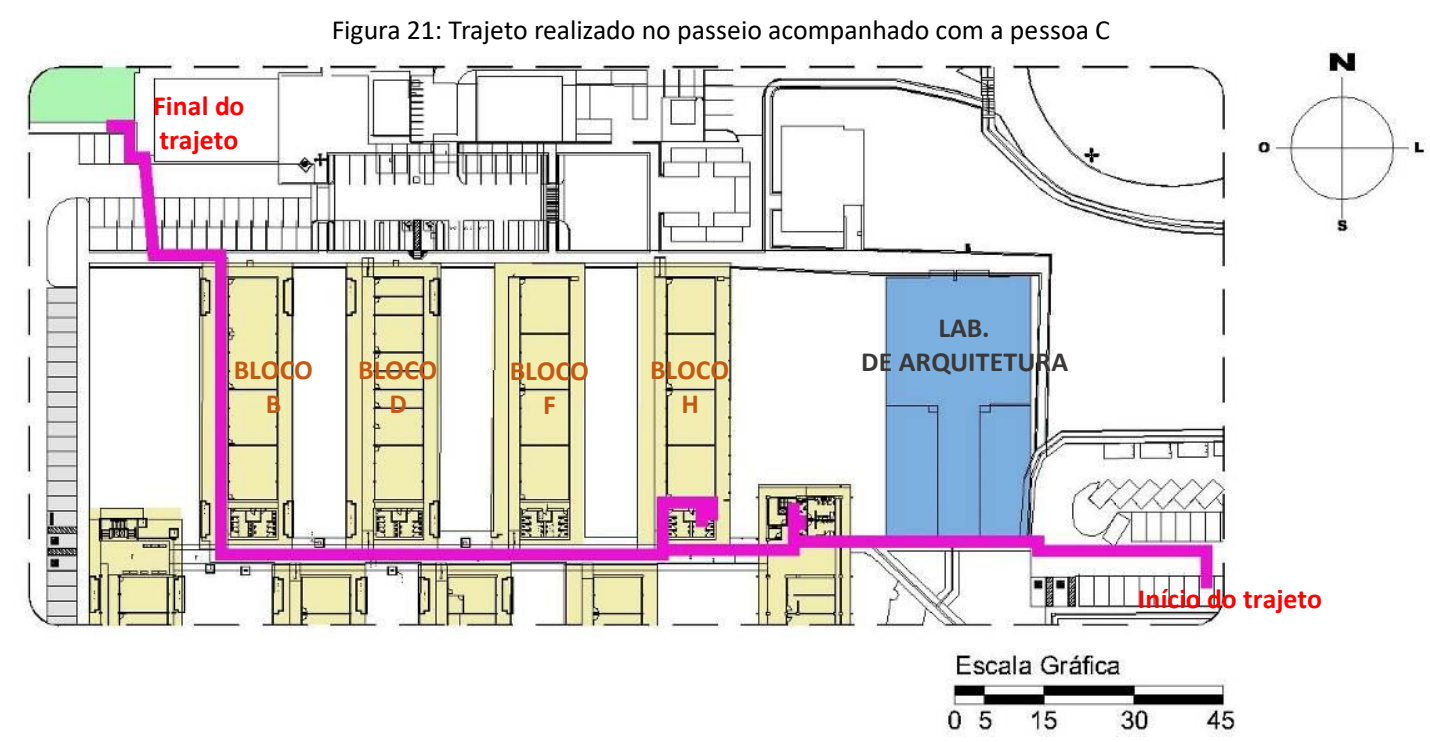

Fonte: Secretaria de Infraestrutura da UFRN editado pelas autoras, 2019.

O passeio foi iniciado no estacionamento (Figura 22) próximo aos laboratórios de Arquitetura e durante toda a atividade foi necessário descrever os ambientes e dar comandos como: "siga em frente", "dobre a direita", "cuidado com uma pessoa a sua direita", dentre outros.

Chamou atenção o fato de o indivíduo alegar sentir uma sensação agradável, uma "brisa fresca", em todos os momentos que passávamos pelas áreas verdes - como a da Figura 23, por exemplo - que existem ao longo da circulação principal do setor IV. O indivíduo afirmava também que nestas mesmas áreas escutava um ruído intenso. Tratavam-se das condensadoras de ar condicionado das salas de aula.

Também foi constatado que a sinalização tátil do piso na área estudada (Figura 24) é insuficiente, e torna perigosa a maior parte dos percursos feitos pelo participante, de modo mais acentuado nos corredores dos blocos de aula, onde se notou a presença de muitos desníveis e nenhuma sinalização (Figura 25). Percebeu-se, também, a ausência de sinalização tátil nas rampas que conectam o corredor principal aos corredores adjacentes, fazendo com que o usuário não utilizasse as rampas de forma segura, levando sustos ao se deparar com elas de forma brusca, já que não era possível o seu prévio reconhecimento.

Ao adentrarmos em um banheiro, o participante afirmou conseguir utilizá-lo, porém foi necessário tatear todo o ambiente interno para, assim, conseguir reconhecer e chegar na cabine da bacia sanitária. Por fim, por mais que a pessoa $\mathrm{C}$ fosse independente quanto à sua mobilidade, observou-se que ela é reduzida devido à ausência de elementos táteis e sinalização, seja ela tátil ou sonora, para pessoas com deficiência visual. Tal fato comprometeu a sua livre e segura circulação em praticamente 


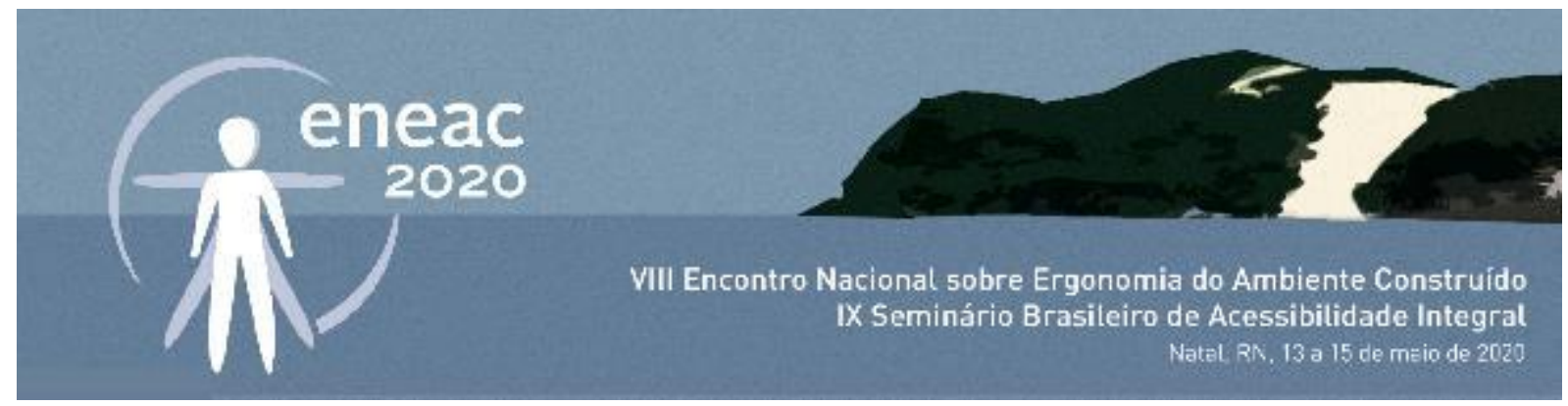

todos os lugares do setor de aulas.

Figura 22: Ponto de partida do passeio acompanhado com a pessoa C estacionamento próximo aos laboratórios de arquitetura

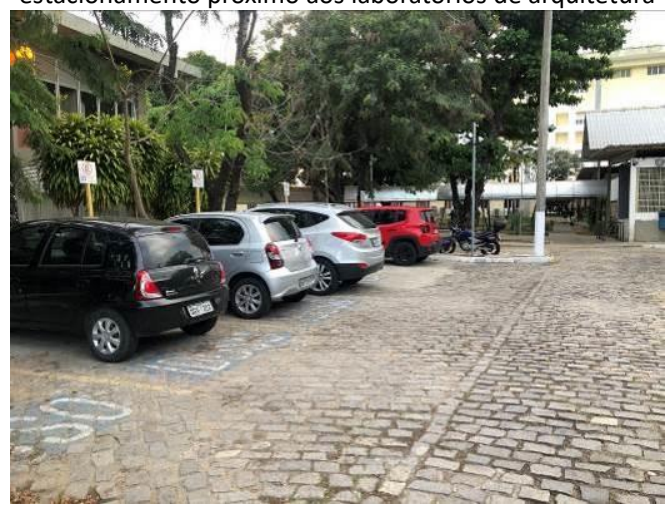

Fonte: Autoras, 2019.

Figura 24: Sinalização tátil insuficiente

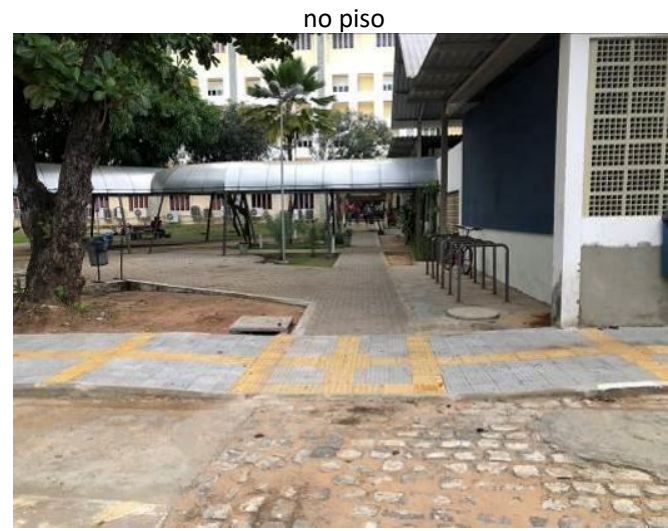

Fonte: Autoras, 2020.
Figura 23: Áreas verdes existentes ao longo

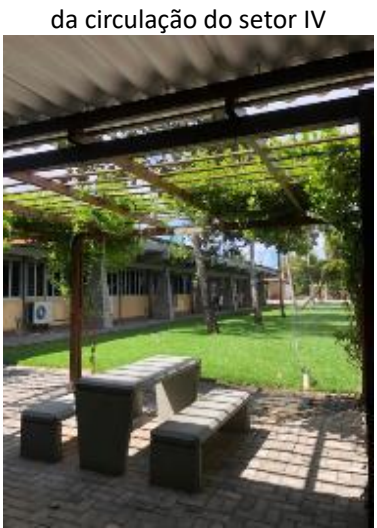

Fonte: Autoras, 2019.

Figura 25: Desníveis ao longo da circulação sem a devida sinalização

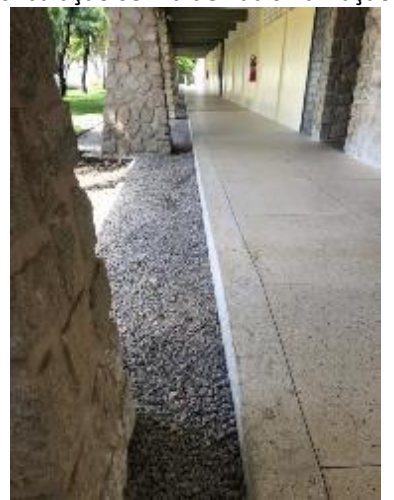

Fonte: Autoras, 2019.

Resumindo os resultados, observa-se que as maiores dificuldades indicadas pelas pessoas com mobilidade reduzida e baixa estatura foram ausência ou altura inadequada de alguns equipamentos de segurança, como a falta de corrimãos nas escadas e rampas e a dificuldade no uso do mobiliário (as mesas e cadeiras nas salas de aula e as bacias sanitárias, nos banheiros).

Já em relação ao participante com deficiência visual, o principal problema foi a ausência de sinalização tátil e/ou sonora ao longo do trajeto definido, principalmente porque ele não estava familiarizado com o espaço e não conhecia a rota a ser percorrida. Isso interferiu diretamente na segurança do usuário, sendo necessária a constante interferência do pesquisador para dar as coordenadas de direção a fim de que que não houvesse nenhum acidente no percurso e fosse possível a conclusão do passeio. 


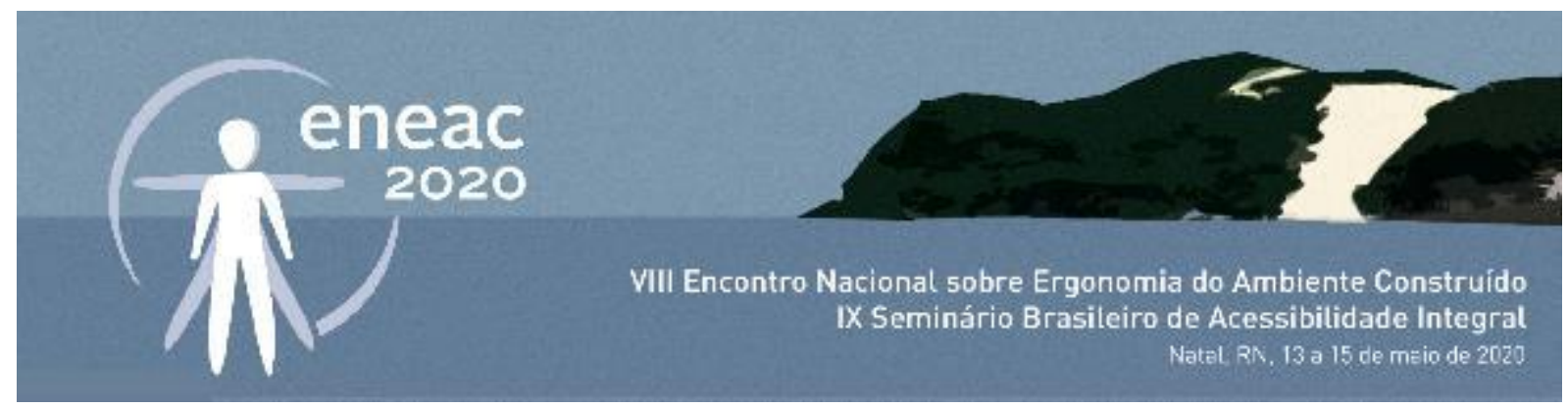

\section{CONCLUSÃO}

Em nossa sociedade, muitas deficiências são negligenciadas, enquanto outras são mais notadas e visíveis aos olhos das pessoas. Todavia, todas elas possuem particularidades e merecem atenção, cuidado e respeito de todos, seja através do cumprimento de legislações vigentes - levando em consideração até as recomendações (itens não obrigatórios) -, seja pela boa manutenção e administração de espaços existentes e respeito às finalidades dos ambientes. Percebendo que, em geral, as deficiências relacionadas à mobilidade (associadas à utilização de cadeira de rodas ou muletas) são mais evidentes e perceptíveis pelas pessoas e, consequentemente, mais comumente abordadas em estudos e discussões sobre acessibilidade, este trabalho buscou abordar outros tipos de deficiência, como a baixa estatura e a cegueira.

Diante desta situação e considerando a importância social da instituição estudada, a diversidade de pessoas e suas respectivas necessidades devem ser levadas em consideração para uma efetiva inclusão social. Para tanto é necessário que, antes de tudo, os profissionais envolvidos em projetos arquitetônicos tenham consciência e respeito aos direitos de acesso e uso dos espaços públicos e privados, e em seguida, que se realizem reformas gradativas para sanar as irregularidades e carências existentes para que os ambientes da universidade possam ser utilizados com segurança e autonomia por todos.

Na investigação realizada por meio dos passeios acompanhados, constatou-se que, no setor de aulas teóricas IV da Universidade Federal do Rio Grande do Norte, não há o cumprimento integral das exigências e condições de acessibilidade determinadas pela norma vigente, a NBR 9050 (ABNT, 2015), que são as condições mínimas para seu funcionamento adequado. Assim, mesmo que ao longo do tempo a instituição venha sendo submetida há diversos processos de reforma e mudanças, os problemas de acessibilidade ainda presentes afetam diretamente a utilização do espaço de forma autônoma e segura pelos seus usuários.

Ou seja, por mais que haja uma preocupação da instituição em tornar o local acessível, tendo em vista o cumprimento parcial de itens obrigatórios pela norma técnica de acessibilidade vigente, várias recomendações como, por exemplo, as barras de apoio em boxes comuns de sanitários coletivos para uso de pessoas com redução de mobilidade (BRASIL, p. 102, 2015), são raramente levadas em consideração na etapa do projeto arquitetônico, embora sejam de extrema importância para um bom uso e satisfação das mais diversas pessoas. Isso é ainda mais evidente com relação a outras condições, para o pleno uso, não "exigidas" nas normas, mas que seriam úteis a usuários com outras dificuldades, como os que participaram dessa investigação. Recomenda-se, portanto, uma análise mais ampla dos ambientes vivenciados cotidianamente por estudantes, funcionários e professores, com especial atenção para suas reais dificuldades - ou seja, tomando como ponto de partida o levantamento das condições dos usuários ali presentes.

Mesmo que este estudo tenha limitações, pois se restringiu ao Setor de aula IV da UFRN, suas conclusões podem ser estendidas às demais dependências da universidade, o que significa, no mínimo, que provavelmente os demais setores de aulas e áreas de convivência da instituição (que correspondem a uma quantidade considerável de área construída), ainda não garantem a efetiva e completa acessibilidade às pessoas com deficiência ou mobilidade reduzida, sendo essencial um olhar mais apurado para suas efetivas condições de uso. 


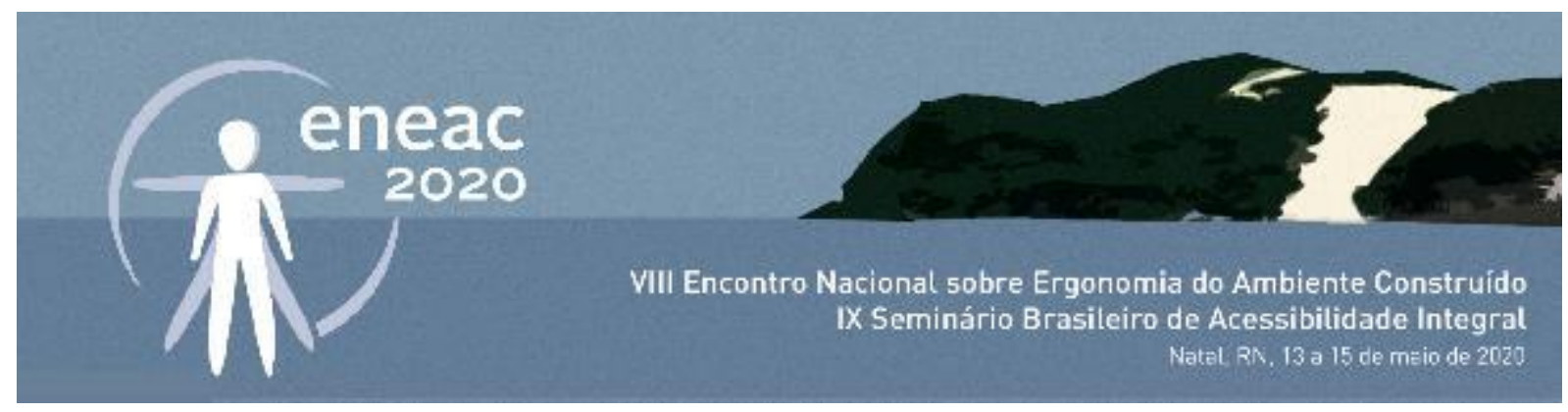

\section{REFERÊNCIAS}

ASSOCIAÇÃO BRASILEIRA DE NORMAS TÉCNICAS (ABNT). NBR 9050: Acessibilidade a edificações mobiliário, espaços e equipamentos urbanos. Rio de Janeiro, 2004.

BRASIL. Decreto no3.076 - Criação do Conselho Nacional da Pessoa com Deficiência (CONADE). Brasília, 1999. Disponível em:<http://www.planalto.gov.br/ccivil_03/decreto/d3076.htm>. Acesso em: 23 jan. 2020

. Decreto no7.612 - Institui o Plano Nacional da Pessoa com Deficiência - Plano Viver sem limite. Brasília, 2011. Disponível em:<http://www.planalto.gov.br/ccivil_03/_Ato2011-2014/2011/Decreto/D7612.htm>. Acesso em: 23 jan. 2020.

.Lei no7.853 - Política Nacional para a Integração de Pessoas com Deficiência. Brasília, 1989. Disponível em:<http://www.planalto.gov.br/ccivil_03/leis/l7853.htm>. Acesso em: 23 jan. 2020.

. Lei no13.146 - Lei Brasileira de Inclusão da Pessoa com Deficiência. Brasília, 2015. Disponível em:<http://www.planalto.gov.br/ccivil_03/Ato2015-2018/2015/Lei/L13146.htm >. Acesso em: 23 jan. 2020

. Política Nacional de Assistência Social - PNAS/2004; Norma Operacional Básica - NOB/Sus. Brasília: Ministério do Desenvolvimento Social e Combate à Fome - Secretaria Nacional de Assistência Social, 2005.

COMISSÃO PERMANENTE DE APOIO A ESTUDANTES COM NECESSIDADES EDUCACIONAIS ESPECIAIS (CAENE). Dados alunos com deficiência [mensagem pessoal - e-mail]. Mensagem recebida por: <inclusão@reitoria.ufrn.br> em 24 jan. 2020.

DISCHINGER,M. Design for all senses: accessible spaces for visually impaired citizens. Thesis (fir the degree of Doctor of Philosophy). Department of Space and Process School of Architecture, Chalmers University of Technology, Götoborg, Sweden, 2000. Disponível em:http://publications.lib.chalmers.se/records/fulltext/1233/1233.pdf. Acesso em: 23 jan. 2020.

ELALI, G. V. M. A.. Avaliação pós-ocupação e responsabilidade social: uma relação a ser sempre (re)discutida. Gestão \& Tecnologia de Projetos, v. 5, n. 2, p.3-17, 11 nov. 2010.

INSTITUTO BRASILEIRO DE GEOGRAFIA E ESTATÍSTICA (IBGE). Censo 2010. Brasília: IBGE, 2012. Disponível em: www.ibge.gov.br. Acesso em: 23 jan. 2020.

ORGANIZAÇÃO MUNDIAL DA SAÚDE (OMS). Relatório Mundial sobre a Deficiência (World Report on Disability). The Worls Bank. (Trad. Secretaria dos Direitos da Pessoa com Deficiência do Governo do Estado de São Paulo), 2012. Disponível em: http://www.pessoacomdeficiencia.sp.gov.br/usr/share/documents/RELATORIO_MUNDIAL_COMPLETO.pdf. Acesso em: 23 jan. 2020

REDE JUNTOS. Censo IBGE: Quem são as pessoas com deficiência do Brasil?, s/d. Disponível em:

https://wiki.redejuntos.org.br/busca/censo-ibge-quem-sao-pessoas-com-deficiencia-do-brasil. Acesso em: 23 jan. 2020.

SANTOS, I. M.; SANTA CRUZ, I. D.; SILVA, J. J.; FIGUEIREDO, L. E.; CALDAS, M. V.; CAVALCANTI, M. A.; MARINHO, M. N.; CASTILHOS, N. C.; Relatório de Avaliação Pós-Ocupação: Setor IV da UFRN. Trabalho Final da Disciplina: Avaliação PósOcupação do Ambiente Construído. Universidade Federal do Rio Grande do Norte. Natal. 2019 (43p).

VILLA, S. b.; SARAMAGO, R. C. P.; GARCIA, L. C. Desenvolvimento de metodologia de Avaliação Pós-Ocupação do Programa Minha Casa Minha Vida: aspectos funcionais, comportamentais e ambientais. Texto para discussão. Brasília: - Instituto de Pesquisa Econômica Aplicada (IPEA), 2016. Disponível em http://repositorio.ipea.gov.br/bitstream/11058/7196/ 1/td_2234.pdf. Acesso em: 24 jan. 2020. 